\title{
Evaluation of Levels of Serum IgE and Rectal Mucosal Eosinophilia in Irritable Bowel Syndrome
}

\author{
Dsra Elif Akkuş, ${ }^{1}$ (D) Sabah Tüzün, ${ }^{2}$ (1) Kayhan Başak, ${ }^{3}$ (D) Kürşat Epöztürk, \\ (D) Mehmet Sayıner, ${ }^{5}$ (D) Mustafa Reşat Dabak ${ }^{2}$ \\ ${ }^{1}$ Mudanya Güzelyalı Family Health Center, Bursa Health Directorate, Bursa, Turkey \\ ${ }^{2}$ Department of Family Medicine, Kartal Dr. Lütfi Kırdar Training and Research Hospital, İstanbul, Turkey \\ ${ }^{3}$ Department of Pathology, Kartal Dr. Lütfi Kırdar Training and Research Hospital, İstanbul, Turkey \\ ${ }^{4}$ Department of Allergy, Kartal Dr. Lütfi Kırdar Training and Research Hospital, İstanbul, Turkey \\ ${ }^{5}$ Department of Medicine, Invova Fairfax Hospital, Falls Church, VA, USA
}

\section{ABSTRACT}

Objectives: Irritable bowel syndrome (IBS) and food allergic reactions are common in the community and can cause symptoms similar to each other. In this study, it is aimed to evaluate serum immunglobulin $E$ (IgE) and rectum mucosal eosinophilia levels in IBS.

Methods: Record of patients who applied between April 2013 and April 2014 were retrospectively screened and patients who were 18-70 years old and previously performed rectal biopsy by colonoscopy and diagnosed with IBS according to Rome III criteria were included in the study. All patients were grouped as diarrheal dominant IBS (IBS-D), constipation dominant IBS (IBS-C), mix type IBS (IBS-M) and unclassified IBS (IBS-U) according to their symptoms. In addition, serum IgE levels and rectal mucosal eosinophilia levels were evaluated from all patients' records.

Results: 39 (56.52\%) of total 69 patients with IBS were in the IBS-C group, 19 (27.54\%) of them were in the IBS-D, $9(13.04 \%)$ of them were in the IBS-M and $2(2.90 \%)$ of them were in the IBS-U. There were not any significant differences between IBS subgroups in terms of presence of allergic disease and presence of food allergy ( $p=0.519$ and $p=0.849$, respectively). The median level of rectal eosinophilia in IBS subgroups was found to be 2.00 (0.00 to 88.00) in IBS-C subgroup, $5.00(0.00-100.00)$ in IBS-D subgroup and $2.00(0.00$ to 11.00$)$ in IBS-M subgroup. In addition, IgE levels were found high in 7 (19.45\%) of IBS-C subgroup, 7 (36.84\%) of IBS-D subgroup and 3 (33.33\%) of IBS-M group ( $p=0.348)$.

Conclusion: In this study, relation between serum IgE and rectal eosinophilia levels with IBS subgroups could not not found.

Keywords: Abdominal pain, defecation, diarrhea, irritable bowel syndrome

\section{INTRODUCTION}

Irritable Bowel Syndrome (IBS) is a functional bowel disease that causes complaints such as chronic recurrent abdominal pain, diarrhea, constipation and swelling in the abdomen and separated into 4 groups as diarrhea dominant IBS (IBS-D), constipation dominant IBS (IBS-C), mix type IBS (IBS-M) and unclassified IBS (IBS-U) ${ }^{[1,2]}$ In the etiopathogenesis of IBS, there are many factors such as damaged gastrointestinal motility, visceral hypersensitivity, inflammation, infections, stress and allergy. ${ }^{[2]}$ Food reactions are common in the community and often 
overlap with each other due to they cause similar clinical

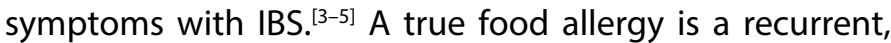
immunologic condition that develops after the eating of certain foods by people sensitive to food allergy. ${ }^{[3,5]}$ Although allergic states diagnosed other than food allergies by well-defined criteria, there are difficulties in diagnosis of food allergies. ${ }^{[3]}$ Euthinophilia and serum lgE level increase, gaita $\mathrm{pH}$, skin tests, basophil histamine release test, intestinal mast cell histamine release test and intestinal biopsy can be used in the diagnosis of food allergy. ${ }^{[5-7]}$ In addition, eosinophil and mast cell reactions may occur in the biopsies taken from the injection site after the injection into the colon mucosa, however this shows poor correlation with skin prick test, serum IgE and IgG4 levels. ${ }^{[8,9]}$ In this study, it is aimed to evaluate serum total lgE level and mucosal eosinophilia levels in rectal biopsies in patients with IBS.

\section{METHOD}

\section{The Universe of the Research}

In the study, record of patients who applied to Kartal Dr Lütfi Kırdar Training and Research Hospital between April 2013 and April 2014 were retrospectively screened and patients who were 18-70 years old and previously performed rectal biopsy by colonoscopy and diagnosed with IBS according to Rome III criteria were included in the study. All patients were classified as IBS-C, IBS-D, IBS-M and IBS-U according to their symptoms. Then, the patients who were included in the study were called by phone and their food allergies was questioned. This study has been approved by Kartal Dr Lütfi Kırdar Training and Research Hospital Ethics Committee (89513307/1009/265).

\section{Measurements of the Study}

Demographic characteristics such as age, gender, body weight, height and smoking conditions of the patients included in the study were questioned and then body mass index (BMI) were calculated. In addition, all patients were called by phone to ask, "Do you think your complaints about your bowel incontinence are related to the foods you eat?", "Are there any foods that increase your complaints about the bowels", "What kinds of foods are discomforting you and cause your complaints" and nutritional allergies were questioned. The biopsy specimens taken during colonoscopic evaluation in our hospital were sent to the pathology laboratory in $10 \%$ formaldehyde solution and the tissue sections taken for follow up after one day fixation were stained by Leica ST5010 Autostainer AXL (Leica Microsystems. Wetzlar, Germany) brand automatic staining device by hemotoxilen-eosine stain and evaluated by Olympus BX53 brand microscope (Olympus, Japan) and then, the eosinophil number were counted in the sections in mucosa in 400 enlargement and number in 1 big enlargement section that has most eosinophils was recorded as score number. Serum total lgE levels of the patients were also measured by the two-step enzymeiinked immunosorbent assay in Beckman Coulter DXI 800 (Beckman Coulter, California, USA) and above of $165.3 \mathrm{IU} / \mathrm{ml}$. were accepted as high.

\section{Exclusion Criteria}

Patients with the history of immune system disorder, parasitary bowel infection, inflammatory bowel disease, coeliac disease, bone marrow transplantation, vasculitis or any kind of cancer and usage of nonsteroidal antiinflammatory, clozapine, rifampicin, carbamazepine, tacrolimus and gold medicine were not included to study.

\section{Statistical Analysis}

SPSS 17.0 statistical software program was used for the statistical evaluation of the data of the study. Frequency, percentage, mean, standard deviation, median, minimum and maximum value were used as descriptive statistical analysis. Continuous variables that not proper to normal variability was assessed by using Mann Whitney $U$ test and Kruskall Wallis test. In the analysis of the categorical variables in the study, chi-square test was used. The $p<0.05$ was considered significant when all data in the study were evaluated.

\section{RESULTS}

$39(56.52 \%)$ of the 69 IBS patients who were included into the study were women, when patients separated into groups, $39(56.52 \%)$ of them were in IBS-C group, 19 $(27.54 \%)$ of them were in IBS-D and $9(13.04 \%)$ of them were in IBS-M and $2(2.90 \%)$ of them were in IBS-U. The mean age of the patients was $40.42 \pm 11.93$ years and the mean of BMI was $27.18 \pm 4.66 \mathrm{~kg} / \mathrm{m}^{2}$ respectively. Smoking was determined in 21 (30.43\%) of the patients and was detected as 11 (28.21\%) in the IBS-C subgroup, 7 (36.84\%) in the IBS-D subgroup and 3 (33.33\%) in the IBS-M group).

When allergic diseases of the patients who participated into study were questioned, a total of $15(21.74 \%)$ allergic disease history were detected in 6 (8.70\%) allergic rhinitis, $6(8.70 \%)$ asthma and 3 (4.34\%) urticaria. It was also found that 34 $(49.28 \%)$ of the patients thought that their complaints were related to food intake. The allergic status of patients according to IBS subgroups were summarized in Table 1.

Median level of rectal eosinophilia was found to be 3.00 (0.00 to 100.00 ) and, the high serum total IgE level was detected in 17 (24.64\%) of all patients in the study. Serum total IgE levels and rectal eosinophilia according to IBS subgroups were summarized in Table 2 . Rectal eosinophilia 


\begin{tabular}{|c|c|c|c|c|c|}
\hline & IBS-C $(n=39)$ & IBS-D (n=19) & IBS-M (n=9) & IBS-U (n=2) & $\mathbf{p}^{*}$ \\
\hline \multicolumn{6}{|c|}{ Allergic disease } \\
\hline Yes & $8(20.51)$ & $6(31.58)$ & $1(11.11)$ & $0(0.00)$ & 0.519 \\
\hline No & 31 (79.49) & $13(68.42)$ & $8(88.89)$ & $2(100.00)$ & \\
\hline \multicolumn{6}{|c|}{ Food allergy } \\
\hline Yes & $18(46.15)$ & $11(57.89)$ & $4(44.44)$ & $1(50.00)$ & 0.849 \\
\hline No & $21(53.85)$ & $8(42.11)$ & $5(55.56)$ & $1(50.00)$ & \\
\hline
\end{tabular}

*Pearson Chi-Kare test. IBS-C: Constipation dominant irritable bowel syndrome; IBS-D: Diarrhea dominant irritable bowel syndrome; IBS-M: Mix Type irritable bowel syndrome; IBS-U: Unclassifiable irritable bowel syndrome. The data were presented as n (\%).

\section{Table 2. Serum total IgE levels and rectal eosinophilia according to IBS subgroups}

\begin{tabular}{lcccc} 
& IBS-C (n=39) & IBS-D $(\mathbf{n = 1 9 )}$ & IBS-M (n=9) & p \\
\hline $\begin{array}{l}\text { Rectal eosinophilia } \\
\text { IgE level, } \mathbf{n}(\%)\end{array}$ & $2.00(0.00-88.00)$ & $5.00(0.00-100.00)$ & $2.00(0.00-11.00)$ & $0.241^{*}$ \\
Normal & $32(80.55)$ & $12(63.16)$ & $6(66.67)$ & $0.348^{\dagger}$ \\
High & $7(19.45)$ & $7(36.84)$ & $3(33.33)$ &
\end{tabular}

${ }^{*}$ Kruskal-Wallis test; ${ }^{+}$Pearson Chi-Kare test. IBS-C: Constipation dominant irritable bowel syndrome; IBS-D: Diarrhea dominant irritable bowel syndrome; IBS-M: Mix Type irritable bowel syndrome. The data were presented as $\mathrm{n}(\%)$ and median (minimum-maximum), where appropriate.

levels of patients with allergic disease were found as 2.00 $(0.00-88.00)$ and $3.00(0.00-100)$ for patients without allergic disease $(p=0.808)$. Median levels of rectal eosinophilia of patients with have complaints about foods were detected as $3.00(0.00-100.00)$ and $2.00(0.00888 .00)$ for patients without complaints $(p=0.841)$. While the IgE median value was $71.00(5.00-524.00) \mathrm{IU} / \mathrm{ml}$ in patients with allergic disease, it was $30.50(1.00-406.00) \mathrm{lU} / \mathrm{ml}$ in patients without allergic disease $(p=0.156)$. The median IgE median value for patients with food-related complaints was as 39.00 (1.00524.00) and the median IgE for patients without complaints was found as $33.00(3.00-384.00)(p=0.312)$.

\section{DISCUSSION}

In this study, relation between serum IgE and rectal eosinophilia levels with IBS subgroups could not not found. In addition, there were not significant differences in the presence of allergic disease and food allergy in IBS subgroups.

IBS is a functional bowel disease characterized by discomfort, swelling and pain in the abdomen which is most frequently encountered in primary health care services and can not be explained by an organic pathology.$^{[1,10]}$ Although the pathogenesis is not fully explained, it is known that in many patients there is a relationship between food intake and IBS symptoms. ${ }^{[6,11]}$ Food allergy is frequently seen in children, in a study it was found to be $3.7 \%$ in adults..$^{[12]}$ There are stud- ies showing that there is a relationship between IBS symptoms and consumption of certain foods. ${ }^{[5,6,11,13]}$ However, it is contradictive that this relationship between symptoms and complaints is due to food allergy or food intolerance. ${ }^{[14]}$ In this study, $21.74 \%$ of patients were found to have an allergic disease and $49.28 \%$ of these complaints were found to be related to food intake. There were not any significant differences between IBS subgroups in terms of presence of allergic disease and presence of food allergy.

IgE-mediated Type 1 hypersensitivity and cell-mediated Type 4 delayed hypersensitivity reactions to developed to certain foods in the development of food allergy play a role. ${ }^{[3,5,14]}$ Despite the immunologic and nonimmunologic barriers of the gastrointestinal system, some food proteins with antigenic properties pass into the blood and interact with IgE antibodies on mast cells in the intestinal mucosa. ${ }^{[15]}$ As a result, bowel permeability, mucus formation, peristaltism, inflammatory cell infiltration are increased and pain fibers are stimulated. ${ }^{[3,15]}$ Clinical reflections of all these changes are seen as nausea, vomiting, abdominal distension, pain and diarrhea. ${ }^{[3,5,15]}$ Although studies have shown that lgEmediated food allergies play a causal role in patients with IBS and there was nor significant difference in serum total IgE levels in patients with IBS in our country. ${ }^{[5,7,7,14,16]}$ In this study, $24.64 \%$ of patients with IBS had IgE were high and no 
significant difference was found between IBS subgroups in terms of IgE levels.

Eosinophils are cells located along the gastrointestinal system except for the esophagus mucosa, and eosinophils found in the intestinal mucosa may play a key role in the immunological response in intestinal hypersensitivity. ${ }^{[5,17]}$ Eosinophils are thought to be effective in IBS related to gastric motility and enteric nerves. ${ }^{[11,18]}$ In a study conducted, although increase in the number of eosinophils in the colon and rectum biopsies of patients with IBS was not detected, in another study showed increased eosinophils in the terminal ileum mucosa. ${ }^{[19,20]}$ In a study, it was also shown that the increase in duodenal eosinophilia may be a marker for atopy, allergy and possibly functional bowel disease, but this is not valid for IBS. ${ }^{[21]}$ In a study conducted in our country, there was not significant difference in the peripheral and tissue eosinophil numbers in the patients with IBS when compared to the control group. ${ }^{[5]}$ Studies have shown that patients with asthma and allergic rhinitis have increased inflammation in the airborne and increased eosinophilia in small bowel biopsies. ${ }^{[22]}$ In addition, mast cells were increased in duodenum and jejunum mucosa in IBS, but there was no increase in eosinophil cells. ${ }^{[23,24]}$ In this study, no significant difference was found between the IBS subgroups in terms of rectal eosinophilia levels.

One of the limitations of the study is the low number of patients and the other limitation is the nutritional allergies of the patients were verbally asked and there was no investigation about it. There are no proven tests that can be used to demonstrate food allergies but skin prick tests and RAST test can contribute to obtain more significant results to support food allergy diagnose in these patients.

In conclusion, there is no definite relationship between IBS and food allergies and allergic diseases, as well as there is a relationship between IBS symptoms and food intake. In this study, relation between serum IgE and rectal eosinophilia levels with IBS subgroups could not not found.

\section{Disclosures}

Peer-review: Externally peer-reviewed.

Conflict of Interest: None declared.

Ethics Committee Approval: The study was approved by the Local Ethics Committee.

Authorship Contributions: Concept - E.E.A., S.T., M.R.D.; Design - S.T., M.R.D.; Supervision - M.R.D.; Materials - E.E.A., K.B., M.S.; Data collection \&/or processing - E.E.A., M.S., K.B.; Analysis and/or interpretation - E.E.A, S.T., K.B., K.Ö.; Literature search - E.E.A., K.Ö.; Writing - S.T., E.E.A.; Critical review - E.E.A., S.T., M.R.D.

\section{REFERENCES}

1. Yao X, Yang YS, Cui LH, Zhao KB, Zhang ZH, Peng LH, et al. Subtypes of irritable bowel syndrome on Rome III criteria: a multicenter study. J Gastroenterol Hepatol 2012;27(4):760-5. [CrossRef]

2. Barbara G, De Giorgio R, Stanghellini V, Cremon C, Salvioli B, Corinaldesi R. New pathophysiological mechanisms in irritable bowel syndrome. Aliment Pharmacol Ther 2004;20 Suppl 2:1-9. [CrossRef]

3. Eswaran S, Tack J, Chey WD. Food: the forgotten factor in the irritable bowel syndrome. Gastroenterol Clin North Am 2011;40(1):141-62. [CrossRef]

4. Crespo JF, Rodriguez J. Food allergy in adulthood. Allergy 2003;58(2):98-113. [CrossRef]

5. Uz E, Türkay C. İrritabl barsak sendromunda gıda alerjisi. Güncel Gastroenter Derg 2006;10(1):38-44.

6. Dainese R, Galliani EA, De Lazzari F, Di Leo V, Naccarato R. Discrepancies between reported food intolerance and sensitization test findings in irritable bowel syndrome patients. Am J Gastroenterol 1999;94(7):1892-7. [CrossRef]

7. Petitpierre M, Gumowski P, Girard JP. Irritable bowel syndrome and hypersensitivity to food. Ann Allergy 1985;54(6):538-40.

8. Bischoff SC, Mayer J, Wedemeyer J, Meier PN, Zeck-Kapp G, Wedi $B$, et al. Colonoscopic allergen provocation (COLAP): a new diagnostic approach for gastrointestinal food allergy. Gut 1997;40(6):745-53. [CrossRef]

9. Shanahan F, Whorwell PJ. IgG-mediated food intolerance in irritable bowel syndrome: a real phenomenon or an epiphenomenom? Am J Gastroenterol 2005;100(7):1558-9. [CrossRef]

10. Agréus L, Svärdsudd K, Nyrén O, Tibblin G. Irritable bowel syndrome and dyspepsia in the general population: overlap and lackof stability over time. Gastroenterology 1995;109(3):67180. [CrossRef]

11. Nanda R, James R, Smith H, Dudley CR, Jewell DP. Food intolerance and the irritable bowel syndrome. Gut 1989;30(8):1099104. [CrossRef]

12. Sampson HA. Update on food allergy. J Allergy Clin Immunol 2004;113(5):805-19. [CrossRef]

13. Simrén $M$, Månsson $A$, Langkilde AM, Svedlund J, Abrahamsson $H$, Bengtsson $U$, et al. Food-related gastrointestinal symptoms in the irritable bowel syndrome. Digestion 2001;63(2):108-15. [CrossRef]

14. Park MI, Camilleri M. Is there a role of food allergy in irritable bowel syndrome and functional dyspepsia? A systematic review. Neurogastroenterol Motil 2006;18(8):595-607. [CrossRef]

15. Isolauri E, Rautava S, Kalliomäki M. Food allergy in irritable bowel syndrome: new facts and old fallacies. Gut 2004;53(10):1391-3. [CrossRef]

16. Barau E, Dupont C. Modifications of intestinal permeability during food provocation procedures in pediatric irritable bowel syndrome. J Pediatr Gastroenterol Nutr 1990;11(1):727. [CrossRef] 
17. Kuzu UB, Köksal AŞ. Eozinofilik gastrointestinal hastalıklar. Güncel Gastroenter Derg 2014;18(3):342-51.

18. Martin ST, Collins CG, Fitzgibbon J, Lee G, Quigley EM, O'Sullivan GC. Gastric motor dysfunction: is eosinophilic mural gastritis a causative factor? Eur J Gastroenterol Hepatol 2005;17(9):983-6. [CrossRef]

19. O'Sullivan M, Clayton N, Breslin NP, Harman I, Bountra C, McLaren $A$, et al. Increased mast cells in the irritable bowel syndrome. Neurogastroenterol Motil 2000;12(5):449-57.

20. Weston AP, Biddle WL, Bhatia PS, Miner PB Jr. Terminal ileal mucosal mast cells in irritable bowel syndrome. Dig Dis Sci 1993;38(9):1590-5. [CrossRef]

21. Walker MM, Salehian SS, Murray CE, Rajendran A, Hoare JM, Negus $R$, et al. Implications of eosinophilia in the normal duodenal biopsy - an association with allergy and functional dys- pepsia. Aliment Pharmacol Ther 2010;31(11):1229-36. [CrossRef] 22. Pires GV, Souza HS, Elia CC, Zaltman C, Carvalho AT, Tortori CJ, et al. Small bowel of patients with asthma and allergic rhinitis: absence of inflammation despite the presence of major cellular components of allergic inflammation. Allergy Asthma Proc 2004;25(4):253-9.

23. Walker MM, Talley NJ, Prabhakar M, Pennaneac'h CJ, Aro P, Ronkainen J, et al. Duodenal mastocytosis, eosinophilia and intraepithelial lymphocytosis as possible disease markers in the irritable bowel syndrome and functional dyspepsia. Aliment Pharmacol Ther 2009;29(7):765-73. [CrossRef]

24. Guilarte M, Santos J, de Torres I, Alonso C, Vicario M, Ramos L, et al. Diarrhoea-predominant IBS patients show mast cell activation and hyperplasia in the jejunum. Gut 2007;56(2):2039. [CrossRef] 